\title{
Hear and Be Heard: Learning With and Through Music as a Dialogical Space for Co- Creating Youth Led Conflict Transformation
}

\author{
Shoshana Gottesman ${ }^{12}$ * \\ 1 Heartbeat \\ 2 The Jerusalem Youth Chorus \\ *shoshibee@gmail.com
}

Received: 29 November 2015 ; Accepted: 25 November 2016 ; Published: 1 March 2017

\begin{abstract}
Israeli, Palestinian, and Palestinian-Israeli ${ }^{1}$ youth who experience the recreation of protracted conflict in a multiplicity of ways through direct and non-direct violence, in addition to intergroup systemic injustice, must learn to witness, name, challenge, and disrupt these extremely powerful societal forces as a means to transform conflict. Transferable learning, in the form of learning for and about peacebuilding, coexistence, coresistence, solidarity, human rights, nonviolent communication, and resilience, when interwoven into the process of learning music with a critical pedagogy (Freire, 1970), can create an opening of spaces (Allsup, 2013) and perspectives in which youth can build equal social relationships.

It is my belief through my own engagement with theory and practice while working with youth in locations of systemic injustice and locations of protracted conflict in Israel/Palestine with the music education-conflict transformation nonprofit Heartbeat, that musical spaces can have profound and enduring effects on youth and their communities. Within these musical spaces in which ensembles learn, rehearse, and co-write lyrics and melodies in dialogue and as reflections of their daily experiences, youth have the potential to author and re-author themselves through a creative process of musicking (Small, 1995). This location of possibilities (hooks, 1994), where youth can question and challenge their socialization, serves as an opening "to read their world" (Greene, 1995), develop critical thinking, and to reimagine their role in society as active participants and stakeholders in transforming conflict. This article also includes excerpts weaved throughout from the youth voices of Heartbeat in the form of their lyrics and actual stories of practice. Ultimately, how can Israeli and Palestinian youth musicians author and re-author themselves through being heard and co-creating musically within these shared dialogical musical spaces, enabling the generating and regenerating of equal social relationships?
\end{abstract}

Keywords: youth, dialogical, musical, spaces, conflict transformation, socialization, equality

\section{Introduction}

I want to watch the sea. Dip my feet in the water.

Dance on the grass. I want to be one with the rays of sun. 
Get me out of here. I want to grow out of this. Dana/Heartbeat - “The Wall” All Rights Reserved. ๑ 2016 Heartbeat, Inc.

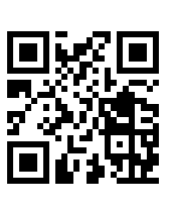

QR Code 1

Heartbeat on Tour Video: https://m.youtube.com/watch?v=VAh7aypeOtM\&feature=youtu.be

The field of conflict transformation is ever growing and expanding as communities across the globalizing modern world become more interconnected and interdependent (Peace Direct, 2015). Nation states, commonly exercising the art of conflict resolution and mitigation as a top-down method, are increasingly not the only actors in mending conflicts and seeking resolutions. With the development of Track II Diplomacy, also known as people-to-people diplomacy, invested individuals at the grassroots level are partaking in transforming conflict by utilizing peacebuilding and human rights education to foster a culture of peace and critically conscious society from the bottom-up. Within the relatively adolescent existence of peacebuilding and human rights education, a younger grassroots practice utilizes the expressive arts, and even more specifically musical spaces, as locations for transferable learning to facilitate the co-creation of youth led conflict transformation.

This calling to use musical spaces, constructed mostly by grassroots music education programs, peacebuilding education programs, or a mix of the two, is sprouting up in locations struggling with protracted environments of direct and indirect violence. In these locations, such as Bosnia-Herzegovina, Israel and Palestine, Afghanistan, Tunisia, and Rwanda amongst many others, conflict transformation is needed to build a positive peace in conflict and post-conflict settings (Schell-Faucon, 2000). Positive peace is the minimization of direct and indirect violence, including structural injustice, leading to "positive visions of peace as being greater than the absence of war" (Barash, 2000, p.146). These programs expressly construct musical spaces in which learning music is not the only end, but in addition a means to an end in constructing ripe educational conditions for transferable learning to take hold. Transferable learning, in the form of learning for and about peacebuilding, coexistence, coresistence, solidarity, human rights, nonviolent communication, and resilience, are interwoven into the process of learning music with a critical pedagogy. Music holds the key to awakening the imagination to create an opening of spaces and perspectives in which to directly foster peace, equality, and one's own responsibility in achieving freedom. These spaces serve as a percolator for youth to hear, be heard, explore their self-expression, and amplify their voices in and between their communities allowing for the cultivation of bottomup generational change.

What are these musical spaces and how are they nurtured into being? What pedagogical processes of learning help to create these locations of possibilities (hooks, $1994)^{2}$ in these dialogical spaces that enable youth in their search for becoming? How can learning fostered in these spaces with and through music transfer beyond the rehearsal room or dialogue circle resulting in an active commitment by youth musicians to witness, name, challenge, and disrupt the extremely powerful societal forces of ethnicity-based conflict socialization? Ultimately, how can musical spaces facilitate the co-creation of youth led conflict transformation?

According to the philosopher of education Maxine Greene, educational philosophy must engage the educator "from his [her] vantage point as actor and from the vantage point of his [her] newest experiences and his [her] most recent fears" (Greene, 1973, p.7). It is my belief through my own engagement with theory and practice while working with youth in locations of systemic injustice such as Harlem and Tunisia, and locations of protracted conflict in Israel/Palestine, that musical spaces can have profound 
and enduring effects on youth and their communities. Within these musical spaces in which ensembles learn, rehearse, and co-write lyrics and melodies in dialogue and as reflections of their daily experiences, youth have the potential to author and re-author themselves through a creative process of musicking (Small, 1995). Musicking can be thought of as the doing and undergoing (Dewey, 1934/2005) of collective "withness" and meaning making through musical encounters as performer and listener. This location of possibilities (hooks, 1994) supporting the process of authoring and re-authoring of the multiple identities and perspectives of youth serves as an opening for youth "to read their world" (Greene, 1995), develop critical thinking, and to reimagine their role in society as active participants and stakeholders in transforming conflict.

Though this current exploration can be applied to many contexts, it is important to first contextualize educational practice and theory, since what works in one context may not prove as successful in another context. For this reason, and my past and current experiences working in non-formal educational settings with Israeli and Palestinian youth musicians of the nonprofit Heartbeat ${ }^{3}$, we will focus on the Israeli-Palestinian conflict as our context. We will explore how Israeli, Palestinian, and PalestinianIsraeli ${ }^{4}$ youth musicians can author and re-author themselves within musical spaces through being heard and co-creating musically. Within this context, trust and understanding is built by sharing equally a space of their own, fostering their agency to name the inequalities and injustices they experience and see in and between their communities. For purposes of clarity, I will often refer to this context as an ethnicity-based conflict or an intergroup conflict, and on occasion refer to conflict as systemic injustice as well. Furthermore, there are additional, sustained music education conflict transformation intergroup programs in Israel/Palestine, such as The YMCA Jerusalem Youth Chorus, The Polyphony Foundation, The Arab-Jewish Orchestra, and so forth, in addition to sustained programs outside of Israel/Palestine such as The West-Eastern Divan Orchestra (Beckles Willson, 2009) and The Mitrovica Rock School through Musicians without Borders in Mitrovica, Kosovo. One could say that all of these programs have "musical spaces," but in the context of this paper, "musical spaces" will specifically refer to sustained programs that address intergroup conflict through critical dialogue and musical co-creation.

Based upon my own experiences as a music education-practitioner working in grassroots music education contexts before entering academia, I commonly discovered a privileging of academic language and understanding over grassroots-practitioner language and understanding. In my opinion and through an activist-oriented lens, the point of researching and sharing findings should not be a battle over language and understanding, but rather to promote a dialogue that invites in all who are interested in contributing to the conversation. It is also worthy to point out that the purpose of this exploration is not to explain the history, politics, and narratives of the Israeli-Palestinian conflict. Though it is important to have a deep understanding of the Israeli-Palestinian conflict and understand the many historical, political, and narrative perspectives of the conflict, it is not what we seek to explain here, but rather the considerations and possibilities when Israeli and Palestinian youth, with their facilitators, co-create a musical space in which to transform conflict. Finally in an attempt to uphold a youthcentered approach, lyrics written by Israeli and Palestinian youth musicians of the Israeli-Palestinian youth music program Heartbeat have been included throughout this article. A short snapshot about each segment of lyrics is included in the QR code ${ }^{5}$, in addition to an accompanying YouTube ${ }^{\circledR}$ video of each song. These stories will provide more context and practical examples of musical spaces through the lens of the program Heartbeat. In general, the music of Heartbeat's youth musicians can be found online on their website (www.heartbeat.fm/) and on YouTube ${ }^{\circledR}$ (https://goo.gl/H633wB).

\section{Implications of Inquiry: Openness to the Emergent}

Though researchers in the fields of conflict resolution and social activism, music enthusiasts, and musicians amongst others have explored music and music education as 
incubators for personal and collective transformations within youth, the literature that currently exists mainly observes the encounter between youth musician participants and the outcomes of the program. There is limited literature that explores the educational process, or the pedagogy, of these spaces, which can explain why music plays a powerful role in youths' lives and in transforming conflict (Oliva \& Charbonnier, 2016). Though this ethnographic research is important, it does not paint a full picture of what is really occurring in these musical spaces because it does not include a critical pedagogy, activist-oriented, or youth-centered lens.

Additionally, the relatively small amount of literature focusing on Israeli-Palestinian peacebuilding and reconciliation programs also only focuses on outcomes without examining the educational process, and usually categorizes youth participants dualistically as either "pro-peace-seeking" or "anti-peace-seeking" (Rosen, 2009). This disadvantages youth participants by suggesting that they perceive their world statically without any nuance, while also discounting that what is peace for one person might not be peace for another person. This approach is limiting, and most likely inaccurate as it designates categories already predetermined by the researcher.

These issues in the existent scholarship focusing on the multidisciplinary grassroots cross-section of youth, conflict transformation, and musical education beg the following questions. What is knowledge and understanding? What knowledge and understanding is privileged over other forms of knowledge and understanding? Who has the authority to speak about this discipline, and to which audience(s)? It is clear that writer and researcher will always wrestle with issues of bias, privileging of knowledge and understanding, and ownership. Explorations within this paper are not without these issues. Through a commitment to inquiry, and approaching the following explorations from a place of activism and invitation to questioning, it is my hope to invite every and any individual into these inquiries to seek more questions beyond the black and white of these very words, and for this entire conversation to be open to what emerges not on its own, but with those who are passionate about musical spaces and youth led conflict transformation.

The multidisciplinary nature of this grassroots practice calls upon a theoretical framework that is able to address this very busy cross-section. Aesthetic education, the process of becoming, and important figures in critical pedagogy Maxine Greene, John Dewey, and Paulo Freire will provide the main framework, while other recognized theories, such as Cosmopolitanism Inheritance (Hansen, 2008), vertical and horizontal identities (Maalouf, 2001), open and closed forms to music education (Allsup, 2013), multimodal critical literacy (Vasudevan, 2013), and conceptualizations of youth (Lesko, 2012), also inform the theoretical framework. Each of these play a role in what I believe is a youth-centered approach to the raising of critical consciousness of Israeli and Palestinian youth in musical spaces. In this location, youth can develop equal social relationships through transferable learning, which can lead to the transformation of conflict.

\section{Pedagogy of Youth Musical Spaces \& Conflict Transformation}

So tired of escaping the truth reading the news and pretending it's all good.

And all I see is these walls that you build,

The humans you kill.

The money spent on building more weapons instead of feeding the poor.

You kill. You take. You grow hatred all around.

Why not grow peaceful generations in this hopeless town? Tell me why?

I'm not asking for a country or a flag. I'm not asking for my land.

I cannot translate my pain into a language you'd understand.

I can't take it no more.

I can't face you no more.

Rasha/Heartbeat - “Hopeless Town”. All Rights Reserved by Rasha Nahas. “Hopeless Town” music video

(c) 2016 Heartbeat, Inc. 


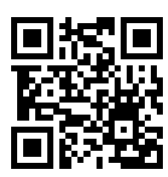

QR Code 2

"Hopeless Town" music video:

https://m.youtube.com/

watch?v=W9vWN9VDm8s\&feature=youtu.be

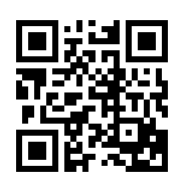

QR Code 3

"Hopeless Town" Snapshot: http://qrs.ly/uw5dd6u

Conflict transformation is a long-term process of generational change. The goal is not simply product-based (two heads of State signing an accord), but rather transforming the attitudes and behaviors through education for and about peacebuilding within society towards building a culture of peace (Bajaj, 2008). According to the Encyclopedia of Peace Education, a "culture of peace" can be defined as a "set of values, attitudes, traditions, and behaviors that ascribe to the notions of freedom, justice, democracy, tolerance, solidarity, cooperation, pluralism, cultural diversity, dialogue and understanding; it also demonstrates a strong respect for all human rights, nonviolence, and fundamental freedoms" (Bajaj, 2008, p. 164). Developing a "culture of peace" requires those involved in conflict to imagine themselves in relationships even with their enemies. It is this recognition of interdependency, or space "in-between" (Greene, 1993), where those in protracted conflict can cultivate the space necessary "to perceive and experience a change process as genuine" (Lederach, 2005, p. 56).

Organizational behavior theorist Margaret Wheatley (2002) says, "nothing in the universe exists as an isolated or independent entity. Everything takes the form of relationship, be it subatomic particles sharing energy or ecosystems sharing food. In the web of life, nothing living lives alone" (p.89). Within a protracted ethnicity-based conflict, this 'web' of human relationships (Arendt, 1958/2013) is under constant threat as conflict recreates itself every day in the education sectors (Bush, K. D., \& Saltarelli, D., 2000), and through political policies, cultural violence (Galtung, 1990), and routine interactions. How can Israeli and Palestinian youth who experience this recreation of protracted conflict in a multiplicity of ways through direct and non-direct violence, in addition to intergroup systemic injustice, challenge and disrupt these extremely powerful societal forces? What role do musical spaces play in facilitating this transformation? How can musical spaces function as an incubator to challenge and disrupt patterns of protracted conflict and systemic injustice, ultimately affecting youth socialization in such a way that they both hold onto their known collective narrative and yet, simultaneously embrace their new narrative? How can youth alter their attitudes and behaviors to look beyond the duality of ethnicity-based conflict by including educational values such as equality, dignity, rights, and freedoms?

This "in-between" (Greene, 1993) is where real-life relationships between youth members can be tested, which requires risk-taking, vulnerability, and creativity of all involved. The ways in which this can occur authentically depends on the space cocreated equally between the youth members involved in co-generating processes of change. And lastly, this co-generation of equal space and equal social relationships must constantly be nurtured, and re-nurtured, reflected and re-reflected upon, and emboldened by individual and collective action.

\section{Ethnicity-based Conflict, Systemic Injustice and Youth Socialization}

Palestine glories in her beauty

The landscape of green polka dots

But what do you say, Palestine?

Why do you look to the sky? 
My beautiful little diaspora

Your walls block the lights of life

But don't worry my beauty

Your towers stand tall above

And the border and the landscape are green

And the blaze of lights dances

Doubting if this is indeed the end

A question that continues in vain

Heartbeat: Haifa 2014-2015 - “Falastine” Lyrics written by Eden, Shai, and Ahiad. All Rights Reserved. () 2016 Heartbeat, Inc.

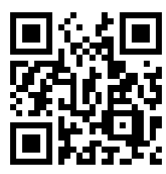

QR Code 4

"Falastine" music video: https://m.youtube.com/ watch?v=rtBxjVh1jg8\&feature=youtu.be

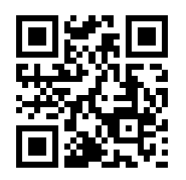

QR Code 5

"Falastine" Snapshot: http://qrs.ly/3o5bi9p

According to writer Amin Maalouf, our vertical identity is the many strands that construct the identity we are born with from birth city and country, religion, language, historical narrative, and culture bestowed upon us by our families. In contrast, our horizontal identity, though influenced by our vertical identity, is built by the influences we pick up over the journey of life, or in other words through our socialization. As we reach an age of making our own decisions, we can affect our socialization through new experiences and communities we join. Our horizontal identity may mirror parts of our vertical identity or it may not. Conflict between the two can lead to personal struggle and also embrace of the "in-between" of the multiple identities we all possess. No strand of ourselves is less true than the other; it is a question of how we make meaning, who we are, and again who we are becoming.

A person's identity is not an assemblage of separated affiliations, nor a kind of loose patchwork; it is like a pattern drawn on a tightly stretched parchment. Touch just one part of it, just one allegiance, and the whole person will react, the whole drum will sound (Maalouf, 2001, p. 26).

It is here that our interest lies in the potential of Israeli and Palestinian youth to determine their own horizontal identities through socialization differing from their vertical identities. This empowerment of choice through education and experiential learning can also challenge how youth are passively understood by the world as they choose to actively be heard. By no means is this a temporary journey, but rather a continuous becoming and growth throughout life, beyond only adolescent years.

What is the role and impact of socialization within ethnicity-based conflicts? Ethnicity-based conflicts are created by violence and systematic exclusion of one identity group over the other for multiple reasons from competition over resources and collective trauma to imposed or felt denial of narrative and nationhood (Kagawa, 2005). In an ethnicity-based conflict, identity often becomes a duality. An individual is either Ethnicity A or an individual is Ethnicity B, and there is no space for anything in between. In the case of the Israeli-Palestinian conflict from a mainstream point of view, one is either Israeli and the Palestinian narrative negates her or his existence, or one is Palestinian and the Israeli narrative negates her or his existence. Both narratives claim that generations upon generations have fought each other for rights to land, freedom, and dignity. Collective history, though of the past, becomes an element of the present in each narratives' socializations. This story of survival and resistance is a pillar in the 
understanding and conceptualization of each ethnicity and how they understand themselves in relation to the Other ethnicity. And with each passing year of conflict, it is aggravated further by atrocious current events, and the forgoing of human rights and justice within the communities of each ethnicity.

In addition to affecting the socialization of youth of both ethnicities, this story is reaffirmed by its retelling over and over again within each ethnicities separate spaces. In the majority of cases, Israeli, Palestinian-Israeli, and Palestinian youth attend separate schools segregated often by ethnicity and religion and typically live in separate neighborhoods even within mixed-cities such as Jerusalem, Haifa, and Jaffa. Israeli citizens, including Palestinian-Israelis, are physically separated by checkpoints and the Separation Barrier from Palestinians who live under Israeli military occupation in the West Bank ${ }^{6}$, and Palestinians who live under Israeli military siege and Hamas-Fatah political lockout ${ }^{7}$ in Gaza. A conflict of this nature includes physical violence and separation, but as well a more menacing strain of violence where the roots of mistrust and hate sown through each narratives' socialization have become so deep that youth on both sides are steadfastly socialized to not see or hear the others' needs, allowing for a continuous blind eye to the oppression, dehumanization, and racism evoked on each other, in often unequal ways.

Whether considered the oppressed or the oppressor in a specific context, this cyclical process keeps these patterns of socialization alive, and proves detrimental to all who are involved, delimiting the ability of both ethnicities to co-create equal solutions (Lazarus, 2015). Those who were once oppressed become the oppressors of others, and "it is only the oppressed who, by freeing themselves, can free their oppressors" (Freire, 1970, p. 56). Freire believes this can only be possible when approached through love, humanization, critical thinking, dialogue, and praxis. When Freire speaks of critical praxis, he is referring to an educational process that combines reflection with action, or "reflection and action upon the world in order to transform it" (Freire, 1970, p.34). These approaches can raise the critical consciousness of the oppressor and the oppressed "to read their world" (Greene, 1995) and challenge, in solidarity, the culture of silence (Freire, 1970) within their communities to foster a culture of peace (Bajaj, 2008).

How does this affect youth members of each ethnicity? Both of these levels of negative peace and systemic injustice are built into youths' vertical identity, and hence their socialization, through overtly visceral objectives and hidden objectives. Without the means and the spaces in which to question these societal forces and exercise praxis, youth are disadvantaged by society through their lack of power. Ledearch describes power as, "a conversation that makes a difference: Our voices are heard and have some impact on the direction of the process and the decisions made" (Ledearch, 2005, p.56). Lesko explains that the lack of youth voice, and hence lack of access to power, in combination with the pressure to "master their environments" (Lesko, 2012, p. 112), can lead to a need for youth to create their own "salvational" (Lesko, 2012) tools in order to act like masters of their own environment. Some might call this acting out, immaturity, passivity, behavioral issues, or in the case of conflict, direct violence, structural violence, and cultural violence (Galtung, 1990), but ultimately it is youth estrangement from themselves in defining and redefining who they are in relation to how the conflict socializes them, and how they are becoming, which leads to this outcome. In locations of protracted conflict and systemic injustice, youth need locations of possibility (hooks, 1994) in which to hear and be heard. Within locations of possibility, youth can author and re-author themselves, personally and collectively, through the constructive "salvational" (Lesko, 2012) tools of musicking in which to master their environments by being heard, seen, and empathized with.

\section{Locations of Possibility}

As a human, I don't realize the reality I live in

You still live in it, and look what it made you into 
Let go of the politician that you are, and leave politics to the people The politicians lead the people when it's supposed to be the opposite The problem isn't the money, the problem is how we look up to it The paper is nice, but it's there for power And what's the use of power if it's used for taking over and controlling Listen up...

You heat yourself with the flame of hope I lit You get from me a lot of pain from what I speak of That's why I call you the Wailing Wall I cry for you, but I feel better then But I expect from you to not only hear what I say But to understand what I mean because in the end We both want the same thing: change the routine This routine that we all are caught into it We have to break this loop that spins around us I'm talking to you, look at me, feel the pain and the shake in my hand This scream of ENOUGH is not enough So I stick to my warm goals which will in the end will lead to peace Moody Kablawi/Heartbeat - "Bubbles" All Rights Reserved by Mohammad Kablawi. "Bubbles" music video $\odot 2016$ Heartbeat, Inc.

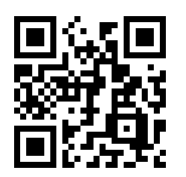

QR Code 6

"Bubbles" music video: https://m.youtube.com/ watch?v=VqcIMXcGDeQ\&feature=youtu.be

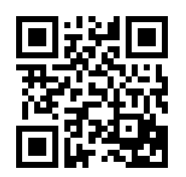

QR Code 7

"Bubbles" Snapshot: http://qrs.ly/x15bi8r

Though it can be argued that youth are put more at-risk in our continuously globalizing world, it can also be argued that through globalization, youth are increasingly attaining access to their voice and agency unlike before. "The nature of globalization's effects, its uneven spread, its accompanying possibilities and injustices, and even the question of whether it is at the end of the day a radically new phenomenon or the continuation of an age-old process continue to be debated vigorously and with feeling" (Stiglitz, 2003, p. 119). Explorations of narrative, digital storytelling and dialogue across differences and within similarities have gained further reach on platforms provided through a more inter-connected world. More than ever, the possibility to express and seek a "multiplicity of affiliations" (Hull et al., 2009, p. 120) stretches beyond the local, and even beyond international borders. Cosmopolitanism, as Appiah (2005) suggests, is not merely universalism, but also "entails respect for legitimate difference" (Hull et al., 2009, p. 120). He explains, "We have obligations to others, obligations that stretch beyond those to whom we are related by the ties of kith and kind, or even the more formal ties of a shared citizenship" (Hull et al., 2009, p.120).

From an educational lens, David Hansen (2008) suggests using the idea of a cosmopolitan inheritance as a way to conceptualize teaching and learning in our globalizing world. A cosmopolitan inheritance, for Hansen, implies educational ${ }^{8}$ loyalty to the local, and the known, while being open to the new, and the unknown. In doing so, "these modes may be in accord with process of socialization, but they do not simply replicate them" (p.298), allowing for education to be "ever incomplete, ever emergent" (p.302). Through a cosmopolitan inheritance, learners gain cosmopolitan sensibilities "that provide all students with opportunities to experience local and broader traditions educationally rather than solely from the point of view of socialization" (p. 300). Cos- 
mopolitan inheritance is by no means only limited to the classroom, and can also be embraced through peer learning and experiential learning.

When co-creating a musical space in which youth agency is fostered for youth led conflict transformation in ethnicity-based conflicts and systemic injustice, youth must question and confront realities of oppressor and oppressed through anti-oppressive pedagogies (Berlack, 2004) and cosmopolitan sensibilities that are awakened with and through music. By musicking (Small, 1995), youth can author and re-author themselves, through exercising the Freirean concepts of problem-posing education (Freire, 1970), critical praxis, dialogue, critical thinking, humanization, and love. This is perhaps the exact location within musical spaces where youth voices can be cultivated to prosper, to be heard amongst their peers and by society to transform conflict.

\title{
Youth and Authoring and Re-authoring in musical Spaces to Unpack Narratives, Challenge Inequity, and Build Equal Social Relationships
}

\author{
Sitting choosing sides \\ No one left behind \\ Sitting choosing sides \\ This conflict in our minds \\ I want find the right way to translate my pain \\ It's startling to drizzle, but fear made it rain \\ want to love you, I want to hate you, \\ want to love you, I want to hate you, \\ Buildings falling down \\ Lost and can't be found \\ Going slowly to an empty home \\ Is this the right place, where did they go? \\ Scared of what? Scared of the truth \\ Scared of what? Scared and confused"
}

Heartbeat: Jerusalem - “Choosing Sides” All Rights Reserved. ๑ 2016 Heartbeat, Inc.

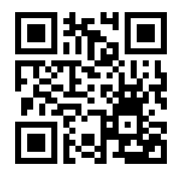

QR Code 8

"Choosing Sides" music video:

https://m.youtube.com/watch?fea-

ture=youtu. $b e \& v=t 9 b P u W s-d d 0$

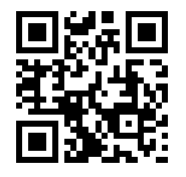

QR Code 9

"Choosing Sides" Overview Snapshot:

http://qrs.ly/uw5dqmp

Though space can be viewed as a tangible location, we will view space as a philosophical location that is translated into practice, and is as well informed by practice where experiences happen and can be learned from. Uncovering this existent bridge between theory and practice suggests an exploration of the "in-between" (Greene, 1993), bringing us to notice and reflect on the unfamiliar- to awaken. According to Greene, "In a society that offers only answers, there is no freedom" (lecture, September 26, 2013). Similarly, John Dewey speaks about the potentiality of experiences as locations for continuous doing and undergoing where ideas, thoughts, and emotions can be constructed and reconstructed through interaction with other objects. The concept of space is an aesthetic opening for imagining and enacting what did not exist before through contextualized meaning-making. Greene (1988) suggests that these spaces situate the very "relation between freedom and the consciousness of possibility, between freedom and the imagination- the ability to make present what is absent, to summon up a condition that is not yet" (p. 16). 
Both Greene and Dewey point to the arts, including music, as an aesthetic experience, empowering individuals to question their world and think critically.

It is because I believe the encounters with the arts can awaken us to alternative possibilities of existing, of being human, of relating to others, of being other, that I argue for their centrality in curriculum. I believe they can open new perspectives on what is assumed to be 'reality,' that they can defamiliarize what has become so familiar it has stopped us from asking questions or protesting or taking action to repair (Greene, 1977, p. 214).

An aesthetic experience allows for "the process of effecting transformations that the human self is created and re-created" (Greene, 1988, p.21), with "continuous formation through choice of action" (Dewey, 1916, p.408). As youth in ethnicity-based conflicts author and re-author themselves through musicking (Small, 1995) within a particular space that is open, while with a supportive structure for creativity, deeper questions are asked and realities are seen and heard that were not considered before. These realities can then be acted upon through the raised critical consciousness (Freire, 1970) of the youth.

From a purely scientific standpoint, we respond to the sounds we hear by engaging almost every region of the brain and producing corresponding emotions (Brooks, 2010). These emotions mirror multiple and nuanced states of human consciousness and feeling, influencing our mood and behaviors.

There are two ways in which this occurs:

1. Emotion Perception (i.e., music makes listeners perceive the emotions that the artist/s or songwriter/s is/are trying to convey through the music)

2. Emotion Induction (i.e., music elicits listeners to feel certain emotions themselves that may be entirely independent of the artist/s' or songwriters' intent) (Brooks, 2010, p.66; Juslin and Laukka, 2004)

Additional research at McGill University's acclaimed neuroscience department discovered that listening to the music we love stimulates the chemical dopamine in our brains "streaming into the striatum region of their forebrains 'at peak emotional arousal during music listening"' (Lasar, 2011). Another recent study (Burns, 2012) suggests that playing music in groups boosts children's ability to empathize with others by fostering empathy skills with and through music-based games. What is really occurring here musically and socially? How can youth utilize music in these spaces to really be seen and co-create, fostering new structures built upon equality, freedom, peacebuilding, coexistence, coresistence? And finally, how does this musical space reach beyond youth's inner world of building equal social relationships to less safe spaces in the outside realities youth face daily in situations of conflict and systemic injustice?

Greene (1973) states, "We philosophize when we can no longer tolerate the splits and fragmentations in our pictures of the world, when we desire some kind of wholeness and integration, some coherence which is our own" (p. 11). Though I do not believe there is one clear process or processes in which to guarantee a transformative breakthrough over a period of time, I am led to consider the following train of thought based upon my theoretical studies and experiences in practice: Through musical authoring and re-authoring and critical dialogue, youth can hear and be heard, and co-create allowing for the unpacking and witnessing of each others' stories, experiences, and realities, fostering critical understanding and empathy that can build equal social relationships. This new socialization can then be shared and witnessed in and between their friends, families, and communities through workshops, live performances, and sharing of their music and media co-creations online. This ultimately brings to the forefront youth voices co-creating as equals critical multimodal literacies, categories, and frameworks challenging the patterns of systemic injustice, dehumanization, racism, and violence within protracted conflict. 


\section{Through Musical Authoring and Re-authoring, Youth can Hear and Be Heard, and Co-create With Their Peers.}

I want to find the right way to translate my pain

I'm not a terrorist

swear that I only pray to God

feel I live alone in this world cuz nobody knows

what happened in Shoufat [refugee camp]

Since the day I was born I didn't know my goals,

But I found a way to express myself and it's my music.

My people don't feel safe anymore

If you want to live you should be a super man.

When I came out to the street, it started raining

Bullets and gas

Very high walls made me feel hopeless and forget who I am.

In my story I'm the champ

Because there's hope, there's the sun

In my story, I'm the champ

Yeah that's right, I'm from a refugee camp.

Hmouda/Heartbeat - "Choosing Sides" All Rights Reserved by Hmouda. "Choosing Sides" music video

(c) 2016 Heartbeat, Inc.

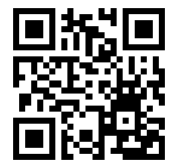

QR Code 10

"Choosing Sides" music video:

https://m.youtube.com/watch?fea-

ture=youtu.be\&v=t9bPuWs-dd0

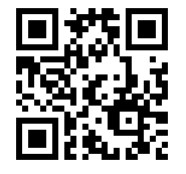

QR Code 11

"Choosing Sides" Hmouda Snapshot: http://qrs.ly/ w65dqmh

According to James W. Carey (2002), there are two types of communication, known as a 'transmission view' and a 'ritual view' of communication. When describing a 'transmission view', Carey states that, "The transmission view of communication is the commonest in our culture- perhaps in all industrial cultures- and dominates contemporary dictionary entries under the term. It is defined by terms such as 'imparting,' 'sending,' 'transmitting,' or 'giving information to others' (p.15). In other words, a 'transmission view' of communication strictly concerns the relationship between the sender and receiver of ideas over a distance in space. The 'ritual view' of communication, tending to be an older influence in society, "is directed not toward the extension of messages in space but toward the maintenance of society in time; not the act of imparting information but the representation of shared beliefs" (p.18). In this case, the sending of a message to a receiver is not of the main focus; it is what the message states and how it is stated that in turn conjoins a community.

When this concept is applied to youth musicking, youth musicians share equal time upon entering the experience of hearing and being heard, which leads to the potential of personal and collective authoring and re-authoring. John Dewey (1934/2005) speaks of shared experiences, especially when encountered within the arts, as a constant, enduring course that runs to fulfillment, but not ending finally in completion and never in cessation. An experience requires intimate interaction with one's environment where there are unions and reunions of thoughts, ideas, and emotions, where an individual "recurrently loses and reestablishes equilibrium with his [or her] surroundings" (p. 46). In these experiences, "every successive part flows freely without seam and without unfilled blanks, into what ensues. At the same time, there is no sacrifice 
of the self-identity of the parts" (p. 47). In the words of Dewey, where everything is already complete, there is no fulfillment.

In Making Music Together: A Study in Social Relationship, Alfred Schutz (1951) points to the act of playing music as a step-by-step uniting experience between co-performers and performer-audience member through the sharing of several dimensions of time, known as inner time and outer time, where all parties are held to a "mutual tuning-in relationship" (p.93). He explains, "It is precisely this mutual tuning-in relationship by which the "I" and the "Thou" are experienced by both participants as a "We" in vivid presence" (p.79).

The differences between inner time and outer time are not so crucial to investigate in this current exploration, but it is important to note why the experience of inner time and outer time matter to co-performers of music. Co-performers, whether soloist and keyboardist, rapper and beatboxer, jazz bassist and percussionist, must be able to communicate together in "withness," with their audience (outer time), while also simultaneously sharing moments of inner time by communicating intimately with each other.

Each of them has, therefore, to take into account what the other has to execute in simultaneity. He/She has not only to interpret her/his own part, which as such remains necessarily fragmentary, but he/she has also to anticipate the other player's interpretation of his/her - the other's - part and, even more, the other's anticipations of his/her own execution. Either's freedom of interpreting [the] composer's thought is restrained by the freedom granted to the other (Schutz, 1951, p. 94-95).

This acknowledgment of "withness" in an authentic face-to-face relationship suggests that co-performers "are sharing not only a section of time but also a sector of space" (p.95).

In other words, it is the humanization of each other, which must be co-created, where the label of "human" becomes greater than ethnicity and vertical identity. It is not that these labels dissolve, but rather co-performers (and performer-audience members) have entered, through a joint experience and space of musicking in literal time, a shared and equal agreement in how they will share with each other deeply, how they will devote to each other musical greatness in co-creating, and how they will respect each others' voices, and therefore rights to freedom and justice. It becomes understood and felt that if one voice is suppressed, then all voices are also suppressed, whether in the rehearsal room, on stage, or on the street. In other words, commitment to one's own freedom and the freedom of other's "means a confrontation with injustice and inhumanity" (Greene, 1973,p. 282-283). Together, co-performers (and performer-listener) can challenge suppression, separation, and speak up for equality and human rights, fostering new locations of possibility (hooks, 1994) with and through musical spaces. In the words of social justice music educators Allsup and Shieh (2012), "A starting point, then: notice inequity. Name the inequity" (p. 48).

\section{Unpacking Through Hearing, Being Heard, and Co-creating}

On my walls, Jerusalem

And you on your walls

$\mathrm{Me}$,

In the attics of my heart

And you in your crumbling fortresses

And the shiny, slippery stones.

Voices of bells, heavy

limp towards me clumsily

And a voice of prayer calls out

And I'm not sure

if it is for good - or bad.

Behind me,

Your poor, tangled houses 
And I am on my walls, watching

And stroking your wounds with a scorched hand

Open your gates, Jerusalem

And I will walk through them

Hesitantly

am on your walls, Jerusalem

And you are on mine.

Reut/Heartbeat - "Al Chamoti - On My Walls" All Rights Reserved by Reut Phillips. "Al Chamoti” music video $\odot 2016$ Heartbeat, Inc.

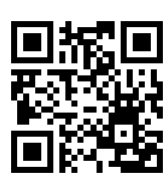

QR Code 12

"Al Chamoti" music video: https://m.youtube.com/ watch?v=W3kBOKTvdQ0\&feature=youtu.be

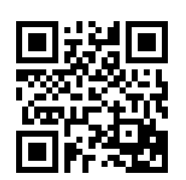

QR Code 13

"Al Chamoti" Snapshot: http://qrs.ly/ke5bi92

The process and ability of youth in conflict and systemic injustice to unpack their narratives, challenge inequity, and build equal social relationships requires a safe or safer space in which to be open to vulnerable experiences and potentially reopening trauma. A lot is at stake, and plenty of mishaps and misunderstandings can happen as youth confront their own understandings of themselves, their realities, and their relations with the Other ethnicity. In light of this, musicians, music educator-facilitators, and grassroots activists must be prepared to "rock with the kid" (Beam, 2013, p. 156) with Freire's critical ingredients of love, care, humility, and solidarity.

For experiences within this space to be creative and constructive in which youth can access their agency and lead conflict transformation, it must be a dialogical place of freedom for youth to question and explore their ideas, narratives, and emotions in communion with their youth peers- where they can continually "identify themselves" (Greene, 1988, p.52) and re-identify themselves within plurality. Freedom in this respect does not mean each person can do whatever they want to do; it is based upon the quality of connection between individuals built through the ability to listen and to hear each other authentically, hence, co-creating a community "of equals where everybody has the same capacity to act" (Arendt, 2013, p. 244). It is a certain embraced responsibility that each youth-member has ownership in this process of building and rebuilding freedom, and that each youth-member has her or his own role to play in making this a possibility collectively. "Not only do we need to be continually empowered to choose ourselves, to create our identities within a plurality; we need continually to make new promises and to act in our freedom to fulfill them, something we can never do meaningfully alone" (Greene, 1988, p. 51). Following the words of Maxine Greene, this musical space must be dialogical.

Paulo Freire speaks of dialogue as "an act of creation" (Freire, 1970) between women and men that must "not serve as a crafty instrument for the domination of one person by another" (Freire, 1970, p. 89), but rather a location of love and, hence, liberation. "Founding itself upon love, humility, and faith, dialogue becomes a horizontal relationship of which mutual trust between the dialoguers is the logical consequence" (Freire, 1970, p. 91). Dialogue must be created and recreated by equal partners within a space who are both willing to "name their world" (Freire, 1970; Greene, 1988). In all cases, these components must be present, otherwise this space cannot be liberatory or transformative, and thus is not dialogical. In the words of Maxine Greene, "only when individuals are empowered to interpret the situations they live together do they become able to mediate between the object-world and their own consciousness, to locate themselves so that freedom can appear" (Greene, 1988, p. 122). According to 
Freire, "In problem-posing education, people develop their power to perceive critically the way they exist in the world with which and in which they find themselves; they come to see the world not as a static reality, but as a reality in process, in transformation" (Freire, 1970, p. 83). In problem-posing education, dialogue is "indispensable to the act of cognition which unveils reality" (Freire, 1970, p. 83).

In the situation of an ethnicity-based conflict like in Israel-Palestine, co-creating this dialogical space of freedom with youth does not happen overnight, and in fact takes several stages over a period of time. These are not linear stages, as in A leads to B which leads to $\mathrm{C}$, and so forth. This is a deepening process that is ritualistic and circular, similar to the shape of a corkscrew. Youth must be constructively put "on edge" to take risks, or in other words, they must embrace vulnerability, musically and through dialogue, by personally and collectively questioning and confronting the conditions of conflict: trauma, erasure, witness(ing), and mourning (Berlack, 2004). This is the place where music plays a big role in the awakening of possibilities for youth involved in conflict to acknowledge these conditions and to unpack them musically and with dialogue, through which critical understanding and empathy can be developed, and eventually equal social relationships. Like the corkscrew example, this process is ongoing, essentially leading youth and their youth peers in doing and undergoing (Dewey, 1934/2005) throughout each stage of building and rebuilding freedom.

According to University of Houston Professor Brené Brown, who researches vulnerability, in order "for connection to happen, we have to allow ourselves to be seen- really seen" (Brown, 2010). These kinds of attention, to see and to be seen, to notice and to be noticed, to hear and to be heard, to care and to be cared for are the building blocks in which vulnerability can be embraced. Berlak (2004) refers to erasure as the failure of individuals "to perceive, recall, and respond with appropriate empathy to evidence of inhumane treatment that is, or has been, right before their eyes" (p. 132). The lack of notice and acknowledgement, the lack of seeing and of hearing, of a minority group or "the other" by the majority, another minority group, or the "enemy" narrative can be challenged musically and then therefore, socially. This lack of notice and acknowledgment occurs on two levels:

1. Believed competition or erasure of one narrative over another for survival or perceived survival.

2. Erasure of current racism, or systemic injustice, in society against one or multiple minorities or narratives within that society.

Both of these levels of negative peace and systemic injustice are built into youths' vertical identity, hence their socialization, and experienced through repetitive trauma and erasure. In either case, each group is delimited by their frames of reference without the languages, categories, or frameworks that are necessary to witness the injustice that is happening. Erasure and therefore dehumanization goes unquestioned (Felman \& Laub, D., 1992). Whether "perpetrator," "victim," or "bystander," which are often not so easily distinguishable labels amidst conflict and many times mix into shades of gray, it is necessary for each to witness the dehumanization and revictimization that they have been a part of and have contributed to. Hearing and being heard within an embraced space of vulnerability as identified by Brown (2010) can enable the beginning or continued "process of mourning that made it possible to witness and integrate the trauma evoked and/or restimulated by the encounter" (Berlak, 2004, p. 136).

Through musicking (Small, 1995), strong bonds can be created that did not exist before, where emotions, stories, and ideas are explored, shared, witnessed, and activated within this dialogical space. The ability to create a vulnerable space with and through music is imperative - where emotions are expressed that otherwise could not be, because of a lack of common language or simply because no words are capable of explaining trauma inflicted upon someone or the inflicting of trauma upon another. The co-creation of a shared musical experience within inner and other time between listener and performer, listener and listener, or co-performers is where youth can experience constructively being put on edge. It is here that empathy and humanization can be es- 
tablished, through deeply witnessing the stories and emotions of another. Witnessing is not merely seeing with one's eyes or hearing with one's ears, but being provoked to full presence to confront erasure and mourn one's previous understanding of her or his world with the new inclusion of the Other's world. It is in these transformative moments that empathy and critical understanding can be developed in order to challenge and disrupt oppressive languages, categories, and frameworks of youths' socializations and to then formulate together new structures and equal social relationships through learning and co-creating critical multimodal literacies, categories, and frameworks as strands of their horizontal identities.

\title{
Co-creating Critical Multimodal Literacies, Categories, and Frameworks in a Dialogical Space and Amplifying them to the Outside World
}

\author{
All day I'm looking through my window and I understand \\ whatever is his is mine and whatever is mine is yours. \\ We are supposed to even be brothers, but to me it seems \\ that doesn't really matter to you. \\ We'll break down the walls, and take down the flags and then we'll \\ discover a world where everything is possible. \\ When we understand that we're all human beings \\ then forever and ever we will be able \\ to live. We will be able to live! \\ Guy/Heartbeat - "Bukra fi Mishmish” All Rights Reserved. ๔ 2016 Heartbeat, Inc.
}

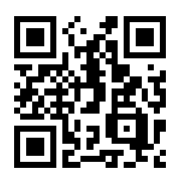

QR Code 14

"Bukra fi Mishmish" music video:

https://m.youtube.com/watch?v=7Xw6Ni-

Ub440\&feature=youtu.be

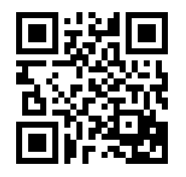

QR Code 15

"Bukra fi Mishmish" Snapshot: http://qrs.ly/ 675bi99

The process of Israeli and Palestinian youth interpreting, analyzing, reading, and questioning their worlds with and through music in a dialogical space is a means of multimodal critical literacy through which youth self-expression has a space to be, even when there are conflicting self-expressions and realities. This space "in-between" is balanced through the quality and deepness of social relationships continuously fostered by youth members, with the understanding that youth members are co-investigators in Freirean-informed dialogue and critical praxis with each other. Ultimately, this results in the respect and value for the truths within each other's stories and experiences (Freire, 1970).

These various modes of self-expression and praxis are all locations of possibility (hooks, 1994) for youth to hear and be heard, and co-create, through the authoring and re-authoring of their understanding of their world and experiencing new literacies, frameworks, and categories to question and challenge their socialization (Gilboa, A., Yehuda, N., \& Amir, D, 2009). When musicking (Small, 1995) is interpreted as an open text for multimodal critical literacies that support the many and multiple ways in which ethnicity-based youth can author and re-author themselves within positive conflict and "withness," co-creating is more than adding sound to the world, but rather the "composing of selves through sound and text" (Allsup, 2013, p. 4). A critical music education pedagogy that supports open-texts provides the space for cosmopolitan sensibilities and curricula, and anti-oppressive pedagogies. In this place of action, youth learn for and about peacebuilding, nonviolence, solidarity, human rights, social jus- 
tice, coexistence, and coresistence. Learning with and through music, youth develop the creative skills and tools through transferable learning in order to transform conflict through their messages, voices, and commitment to the freedom of each Other.

Through composing (Allsup, 2013) with a critical music education pedagogy and cosmopolitan sensibilities, youth can actively challenge the patterns of current unequal and structurally violent systems by co-creating new structures, frameworks, and languages that are dependent on equality, human rights, coexistence, and coresistence. This can be through many means of composing, including multiple ways of composing at the same time. For example, self-expression through songwriting lyrics, rhythms, harmonies, and melodies, creating musicals, singing, writing sonatas, spoken word, improvising, producing music videos, sampling, instrumental performing, rapping, beatboxing, sound installations, DJing, and so forth are all ways of creating and co-creating. When infused with youth messages of social activism and presented to their communities, these new languages, frameworks, and categories can reach beyond the rehearsal room and intimate meeting spaces of youth peers to be heard in less safe spaces in youths' communities.

Finally, how do youth in an ethnicity-based conflict amplify their messages and voices beyond the equal space they continually co-create amongst each other? How does interaction with their communities in turn affect youths' own co-creating of equal space? Historically, music has been used in various forms of social activism, such as protest music and collective singing. Multiple social movements striving for social justice, civil rights, solidarity, and human rights, such as the Civil Rights Movement in America and the New Song Movement in Latin America, built a sense of belonging to something larger and gained strength when communicated with and through music. Protest music and collective singing "reinforces feelings of belonging to a larger community, something larger than themselves and empowers activists to believe that they can ultimately affect change" (Brooks, 2010, p. 68). The advent of social media, such as Facebook ${ }^{\circledR}$, Twitter ${ }^{\circledR}$, and YouTube ${ }^{\circledR}$ has amplified in particular the potency and space for the messages of collective singing and protest songs even further through the ability to inspire millions to be put "on edge" in raising their voices and joining in the call for social change and equity. Growing up with the world of social media and new media, research shows that youth are the most adept at using these new technological tools to their advantage in order to be heard by their communities.

As we have reviewed, the act of musicking (Small, 1995) between youth in an ethnicity-based conflict can build and rebuild equal social relationships in "withness" when dialogical, where all involved equally agree to "name their world" (Freire, 1970) and commit to the communion of each other's freedom. The next step is for youth to take their messages and co-creations into their communities. By composing (Allsup, 2013), youth's authoring and re-authoring can be shared beyond their inner space to less safe spaces from everyday interactions within their family, schools, and communities through live cultural productions, such as performances and workshops to multimedia through new media and social media, such as YouTube ${ }^{\circledR}$, SoundCloud $\AA$, Instagram ${ }^{\circledR}$, and Facebook ${ }^{\circledR}$ amongst other social networks. Here, Israeli and Palestinian youth can be "active, inventive, creative beings, busy making what sense of it they can, drawing on the local and global cultural resources to which they have access" (Hull et al., 2009, p. 134).

In addition, these self constructions and re-constructions are not limited to only online presence, but rather intertwined with everyday life as these forms of new and social media have become texts in Israeli and Palestinian youth members' daily being in formal and non-formal education settings. Just as youth culture is expressed, and at the same time influenced by music on these new media and social media sites, Israeli and Palestinian co-created youth cultures have the potential to influence their social media surroundings and be challenged by them. In addition, since youth culture has the power to create and recreate itself quicker than ever before, this also signals that Israeli and Palestinian co-created youth culture has the ability to spread more quickly and further than ever before. Whether this happens in the form of a young Palestinian 
rapper that uploads her outlet of self-expression onto SoundCloud ${ }^{\circledR}$, a joint Israeli and Palestinian youth musician quartet uploading their performance of Beethoven's String Quartet Op. 127 onto YouTube ${ }^{\circledR}$, an Israeli youth jam band sharing their personal countdown of favorite artists, social activists, or whoever on Facebook® or Twitter®; Israeli and Palestinian youth can amplify their reading of their world into new spaces in which to hear and be heard, and co-create. This platform extends their new critical multimodal literacies, categories, and frameworks beyond the rehearsal room of equalizing space and building of equal social relationships, but into the larger space of global everyday interactions.

\section{I am What I am Not Yet; We are What We are Not Yet}

As this current exploration of musical spaces and youth led conflict transformation comes to a close, it is important to touch upon a few loose ends. In particular, these include addressing the quality of the educational process, limitations by physical boundaries, structural boundaries, ideological boundaries, and finally where additional scholarship is needed. Each of these will be explored briefly.

\section{The Quality of the Educational Process}

In many ways the ability of youth to lead conflict transformation depends on the quality of the social relationships built between youth members, and the quality of the educational process through which knowledge and understanding can be shared between youth members, and youth members and facilitators. It is possible, as Hansen (2008) says, that youth members "will carry sensibilities with them wherever they go" (p. 304). Certainly this is the hope, though of course most progressive educators who follow John Dewey, Parker Palmer, and Maxine Greene will agree that there is no guarantee whether or when a transformative educational breakthrough will happen. To quote Hansen again,

A cosmopolitan sensibility is not a possession, not a badge, not a settled accomplishment or achievement. It is an orientation that depends on the ongoing quality of one's interactions with others, with the world, and with one's own self. Like education itself, it is ever incomplete, ever emergent (p. 302).

Based upon my experiences and the writings of Dewey, Greene, and Freire, the quality of interactions and educational process depends on providing an "(e)quality of experiences" within an open-text, youth-centered approach to teaching and learning with a critical music education pedagogy fused with anti-oppressive pedagogies. This suggests a musical space that is open for youth voices to express their learning interests, while also supporting peer learning, experiential learning, and horizontal learning. Ultimately, learning and teaching in these musical spaces should be catered and contextualized to the needs of the youth. For this reason, the processes of learning and teaching will look similar, and yet uniquely different within each youth group of Israelis and Palestinians, since each youth groups' interests and needs will depend on their personal experiences, interests, and what they bring to the table.

\section{Israeli and Palestinian Youth Physical and Structural Boundaries}

We are hungry for the truth.

You are willing to fight to prove you're right.

You are thirsty to know.

You will write everything on stone.

What do you do when you can't find a label? When someone doesn't fit your box?

Well let me save you some time. There is more than two colors in your simple mind.

Let's make a toast all together.

Let us drink from this glass of poison.

You want so badly to know. 
That the road you chose is correct.

So you'll bend the facts, shut your eyes, close your ears.

Close your ears.

Neomi/Heartbeat - “Make a Toast”. All Rights Reserved by Neomi Zahor.

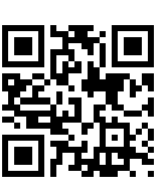

QR Code 16

"Make a Toast" Snapshot: http://qrs.ly/xs5bigf

The ability for Israeli and Palestinian youth to lead conflict transformation hinges upon the ability for each ethnicity to arrive at their agreed meeting space safely, physically and emotionally, and on time with their musical instruments and other accessories. There are many physical and structural boundaries that affect and inhibit the ability of movement for each ethnicity, though often unequally. These forms of systemic injustice, whether physical boundaries such as a wall or checkpoint, structural boundaries such as walking in the wrong neighborhood leading to police frisking or the throwing of rotten items, or even emotional boundaries of perceived threat, are all challenges to the sustainability of youth members' interactions. Even within a mixed city, such as Jerusalem, Jaffa, or Haifa, it is difficult to choose a common location that is not inflicted with these boundaries of systemic injustice. Moreover, another structural boundary is the drafting of Israeli youth into the Israeli army at the age of 18, whereas Palestinian-Israeli and Palestinian youth do not go to the army, are not allowed to enter the army, or are against joining the army. Instead, they enter the work force or apply for university. This direct separation of both youth ethnicities from each other creates additional barriers and challenges to their continued activism post high school.

\section{Ideological Boundaries of Israeli and Palestinian youth}

Besides the challenging ideological hurdles of youth socialization that youth must overcome in order to transform conflict, there is also a need to address the newest ideological boundary affecting the Israeli-Palestinian conflict, which is the issue of normalization. According to the Boycott, Divestment, and Sanction (BDS, 2007) ${ }^{10}$ movement, normalization is

the participation in any project, initiative or activity, in Palestine or internationally, that aims (implicitly or explicitly) to bring together Palestinians (and/or Arabs) and Israelis (people or institutions) without placing as its goal resistance to and exposure of the Israeli occupation and all forms of discrimination and oppression against the Palestinian people.

Debating whether the BDS movement is the correct method for social change, conflict transformation, or even ending the occupation is beyond the scope of this current exploration. It is important to clarify that utilizing musical spaces for Israeli and Palestinian youth led conflict transformation can be perceived as an act of normalization, yet in many ways when cultivated with a critical and anti-oppressive pedagogy will not fit the categories of normalization or anti-normalization. In line with the views of Maxine Greene of the importance of pushing beyond dualities and the views of Paulo Freire of resisting a culture of silence (Freire, 1970), these musical spaces we refer to in this exploration are locations of possibility for questioning, challenging, and resisting. Again in the words of Maxine Greene (1977),

If the uniqueness of the artistic-aesthetic can be reaffirmed, if we can consider futuring as we combat immersion, old either/ors may disappear. We may make possible a pluralism of visions, a multiplicity of realities. We may enable those we teach to rebel (p.295). 


\section{Conclusions and Looking Ahead: Additional Room for Study and Emerging Possibilities}

In summary, musical spaces have the potential to challenge intergroup youth to re-examine, re-learn, and question their socialization, which continues to enable protracted conflict on a daily basis whether from routine interactions, systemic injustice, and increasingly "causal" wars. By co-constructing an equalizing space through a critical pedagogy, Israeli and Palestinian youth can truly learn about each other's narratives, identities, fears, and joys while in dialogue and co-creating multimodal reflections of their realities in "withness." This unique space in which "to become," and be fully oneself also gives youth ownership over their own authoring and re-authoring with and through music. Transferable learning, in the form of learning for and about peacebuilding, coexistence, coresistence, solidarity, human rights, nonviolent communication and resilience, gained through dialogue and co-creation can then be utilized by youth musicians and singers in less safe spaces outside of the rehearsal room and dialogue sessions. The strength of this binational community where music is not only the reflection of their reality, but also the creation of their reality has the potential to transcend conflict through song, lyrics, YouTube ${ }^{\circledR}$ videos and SoundCloud ${ }^{\circledR}$ accounts, local and international workshops and performances, and equal social relationships.

There is plenty more waiting further exploration beyond this this inquiry-practitioner narrative reflection. A few of these topics include looking at specific music education methods and practices that are connected to co-creating a dialogical musical space, exploring the idea of transferable learning further and how it relates to pedagogy, inquiry-practitioner and participant observer research of grassroots music education, and/or peacebuilding programs working with Israeli and Palestinian youth, and the list continues.

It is easy to say that the future of the Israeli-Palestinian conflict looks bleak and uncertain. What is clear is the need to continue to (re)invent, (re)extend, (re)generate, and (re)revise our notions of reality, and surely we cannot do this alone. Israeli and Palestinian youth have the power to challenge the status quo of violence, separation, occupation, and inequality by pushing the boundaries in and between their communities to seek the unknown and the stranger hidden behind walls, checkpoints, and fear. It will be a long-term process, perhaps even a life project, but every day is a potential day for both Israeli and Palestinian youth to co-create change.

This notion of youth-led conflict transformation with and through musical spaces extends beyond the context of Israeli and Palestinian youth, and is indeed applicable and relevant to youth throughout the world seeking to hear and be heard in locations of conflict and systemic injustice. Dialogical musical spaces, filled with consonances and dissonances, love, harmonies, care, rhythms, humility, sound and solidarity, are liberatory places in which youth can imagine and proactively co-create locations of possibility.

\section{Acknowledgements}

Hear and Be Heard is written in honor of Israeli and Palestinian youth musicians and artists doing the hard work to be heard and alter their realities by challenging the status quo. It is also written in memory of my late father Jerry-Yoram Gottesman.

\section{Notes}

1. Palestinian-Israelis are Arab-citizens of the State of Israel who culturally, socially, and politically identify as Palestinians. Their ancestral home is Palestine, which is now the current State of Israel.

2. bell hooks is the pen name of author, feminist, and social activist Gloria Jean Watkins. She insists her pen name be written all in lower case. (bell hooks. (n.d.). In Wikipedia. Retrieved from https://en.wikipedia.org/wiki/Bell_hooks\#cite_note-pen-name-1 
3. Heartbeat creates spaces and opportunities for Palestinian and Israeli youth musicians to build critical awareness, respect, and trust while harnessing creative nonviolent tools for self-expression and social change. Heartbeat has two youth ensembles, one in Haifa and in Jerusalem, and a Graduate Program for young musicians from Jerusalem, Haifa, Tel AvivJaffa, and the surrounding areas. The youth program meets once a week throughout the school year, has two retreats, several field trips, and occasionally international exchanges. Each ensemble has one pair of Palestinian and Israeli co-facilitators who are musicians and music educators.

4. Palestinian-Israelis are Arab-citizens of the State of Israel who culturally, socially, and politically identify as Palestinians. Their ancestral home is Palestine, which is now the current State of Israel.

5. A QR code is a machine-readable text consisting of black and white squares in differing patterns. When using a QR reader application on a smart phone, the application interprets the square and presents the information held within the square into a readable format. A free QR reader application that can be used for the purpose of this paper is "QR Reader."

6. East Jerusalemite Palestinians have a different identity status from Occupied West Bank Palestinians and Palestinian-Israelis, which affects their rights and freedoms. East Jerusalem was annexed in 1967, though its status is still undefined as Jerusalem is a final status negotiation issue. East Jerusalemites do not have citizenship, but rather a permanent residency card issued by the Israeli government. Many East Jerusalem Palestinians consider themselves to be occupied by Israel.

7. Though Hamas governs Gaza currently, it was originally co-governed by both Hamas and Fatah. In 2006 through an attempt to alter this situation, relations between Hamas and Fatah fell out. In light of this, Fatah also contributed to the current Hamas political lockout in Gaza.

8. Here, educational refers to understanding and knowledge or knowing.

9. Quoted from William Pinar's organized systematic study of Maxine Greene's writings and contributions (Pinar, 1998, p. 1).

10. The Boycott, Divestment, and Sanction movement, from now on referred to by its acronym BDS, is explained on their website as, "The global movement for a campaign of Boycott, Divestment and Sanctions (BDS) against Israel until it complies with international law and Palestinian rights was initiated by Palestinian civil society in 2005 , and is coordinated by the Palestinian BDS National Committee (BNC), established in 2007. BDS is a strategy that allows people of conscience to play an effective role in the Palestinian struggle for justice." (http://www.bdsmovement.net/bdsintro)

\section{References}

Allsup, R. E. (2013). The compositional turn in music education: From closed forms to open texts. Composing our future: preparing music educators to teach composition, 57-70. https://doi.org/10.1093/acprof:oso/9780199832286.003.0004

Allsup, R. \& Shieh, E. (2012). Social justice and music education the call for a public pedagogy. Music Educators Journal, 98(4), 47-51. https://doi.org/10.1177/ 0027432112442969

Appiah, K. A. (2005). The ethics of identity. Princeton, NJ: Princeton University Press.

Arendt, H. (2013). The human condition. Chicago: University of Chicago Press.

Bajaj, M. (Ed.) (2008). The encyclopedia of peace education. Charlotte, N.C.: Information Age Publishing

Barash, D. (2000). Building “positive” peace. In D. Barash (Ed.), Approaches to peace: A Reader in peace studies, 1-4 (pp. 146-187). Oxford: Oxford University Press.

Beam, C. (2013). To the end of June: The intimate life of American foster care. Houghton Mifflin Harcourt. 
Beckles Willson, R. (2009). Whose utopia? Perspectives on the West-Eastern Divan Orchestra. Music and Politics, 3(2),1-21. http://dx.doi.org/10.3998/mp.9460447.0003.201

bell hooks. (n.d.). In Wikipedia. Retrieved from https://en.wikipedia.org/wiki/ Bell_hooks\#cite_note-pen-name-1

Berlak, A. (2004). Confrontation and pedagogy: Cultural secrets, trauma, and emotion in antioppressive pedagogies. In M. Boler (Ed.), Democractic dialogue in education: Troubling speech, disturbing silence (pp. 123-144). New York: Peter Lang.

Brooks, J.R. (2010). "Peace, salaam, shalom": Functions of collective singing in U.S. peace activism. Music and Arts in Action 2.2. Retrieved from http://musicandartsinaction.net/ index.php/maia/article/view/antiwarsongs

Brown, B. (TED Talk). (2010, June). The power of vulnerability. Podcast retrieved from https://www.ted.com/talks/brene_brown_on_vulnerability

Burns, J. (2012, June, 12). Group music lessons 'may boost empathy in children'. BBC News. Retrieved from http://www.bbc.com/news/education-18412409

Bush, K. D., \& Saltarelli, D. (2000). The two faces of education in ethnic conflict: Towards a peacebuilding education for children (No. innins00/7).

Carey, J. (2002). A cultural approach to communication. In D. McQuail (Ed.) McQuail's reader in mass communication theory, (pp. 36-45). London: Sage Publications.

Charbonnier, L., \& Oliva, F. (2016). Conflict analysis handbook: A field and headquarter guide to conflict assessments. Retrieved from http://www.unssc.org/home/themes/peace-security/ conflict-analysis-handbook

Dewey, J. (1916). Democracy and Education: An Introduction to Philosophy of Education. Macmillan

Dewey, J. (2005). Art as experience. New York: Penguin.

Felman, S., \& Laub, D. (1992). Testimony: Crises of witnessing in literature, psychoanalysis, and history. New York: Taylor \& Francis.

Freire, P. (1970). Pedagogy of the oppressed. M. B. Ramos (trans). New York: Continuum.

Galtung, J. (1990). Cultural violence. Journal of Peace Research, 27(3), 291-305. https://doi.org/10.1177/0022343390027003005

Gefen, G. (2011). Bukra fi mishmish. (Single). Haifa, Israel/Palestine: Heartbeat, Inc.

Gilboa, A., Yehuda, N., \& Amir, D. (2009). Let's talk music: A musical-communal project for enhancing communication among students of multi-cultural origin. Nordic Journal of Music Therapy, 18(1), 3-31. https://doi.org/10.1080/08098130802610999

Greene, M. (1973). Teacher as stranger (p. 6). Belmont, CA: Wadsworth.

Greene, M. (1977). The artistic-aesthetic and curriculum. Curriculum Inquiry,6 (4), 283-296.

Greene, M. (1988). The dialectic of freedom. New York: Teachers College Press.

Greene, M. (1995). Releasing the imagination: Essays on education, the arts, and social change. San Francisco: Jossey-Bass.

Greene, M. (1993). Diversity and inclusion: Toward a curriculum for human beings. Teachers College Record, 95(2), 211-221.

Hansen, D. T. (2008). Curriculum and the idea of a cosmopolitan inheritance. Journal of Curriculum Studies, 40(3), 289-312. https://doi.org/10.1080/00220270802036643

Heartbeat: Jerusalem (2015). Hopeless Town. [Single]. Haifa, Israel/Palestine: Heartbeat, Inc. Hmouda, M. (2015). Hopeless Town. [Single]. Haifa, Israel/Palestine.

hooks, b. (1994). Teaching to transgress: Education as the practice of freedom. Vol. 4. New York: Routledge.

Horton, M., Freire, P., Bell, B., \& Gaventa, J. (1990). We make the road by walking: Conversations on education and social change. Philadelphia, PA: Temple University Press.

Hull, G., and J. Zacher. "L. Hibbert. (2009). Youth, risk, and equity in a global world." Review of Research in Education, 33,117-159. https://doi.org/10.3102/0091732X08327746 
Juslin, P. N., \& Laukka, P. (2004). Expression, perception, and induction of musical emotions: A review and a questionnaire study of everyday listening. Journal of New Music Research, 33(3), 217-238.

Kablawi, M. (2015). Bubbles. Moody Kablawi and Touring Band 2015. Single. YouTube. Washington, D.C.: Heartbeat, Inc.

Kagawa, F. (2005). Emergency education: A critical review of the field. Comparative Education, 41(4), 487-503. https://doi.org/10.1080/03050060500317620

Lazarus, N. (2015). Intractable peacebuilding: Innovation and perseverance in the IsraeliPalestinian context. George Mason University School for Conflict Analysis and Resolution, Working Paper 28.

Lederach, J. P. (2005). The moral imagination: The art and soul of building peace. Oxford: Oxford UP. https://doi.org/10.1093/0195174542.001.0001

Lesko, N. (2012). Act your age!: A cultural construction of adolescence. (2 nd Edition) New York: Routledge.

Maalouf, A. (2001). In the name of identity: Violence and the need to belong. New York: Arcade Publishing.

Lasar (2011, January 18). Turns out that music really is intoxicating, after all. Retreived from http://arstechnica.com/science/2011/01/turns-out-that-music-really-is-intoxicating-afterall/

Nahas, R. (2014). Hopeless Town. [Single]. Caesarea, Israel/Palestine.

Palestinian BDS National Committee (BNC). (2007, November, 21). Boycott, divestment, sanction movement. Retrieved from http://www.pacbi.org/atemplate.php?id =100

Peace Direct. (2015). Peace Direct strategy papers (June 2015). London: Peace Direct.

Phillips, R. (2014). Al Chamoti. [Single]. Jerusalem, Israel/Palestine.

Pinar, W. (Ed.). The passionate mind of Maxine Greene:" I am--not yet". Psychology Press.

Rosen, Y. (2009). Transformation of central and peripheral beliefs in the eyes of the "Other" challenges for peace education. Journal of Transformative Education, 7(2), 134-145. https://doi.org/10.1177/1541344609339023

Schell-Faucon, S. (2000). Conflict transformation through educational and youth programmes. Berghof Handbook for Conflict Transformation: Conflict Transformation through Educational and Youth Programmes. Retrieved from http://www.berghof-handbook.net/documents/ publications/schell_faucon_hb.pdf

Schütz, A. (1951). Making music together: A study in social relationship. Social Research, 18, 76-97.

Small, C. (1995). Musicking: A ritual in social space. A lecture at the University of Melbourne June 6.

Stiglitz, J. E. (2003). Globalization and its discontents. New York: Norton

Vasudevan, L. \& DeJaynes, T. (Eds) (2013). Arts, media, and justice: Multimodal explorations with youth. Peter Lang: New York.

Wheatley, M. J. (2002). Turning to one another: Simple conversations to restore hope to the future. San Francisco: Berrett-Koehler Publishers.

Zahor, N. (2014). Make a Toast. [Single]. 